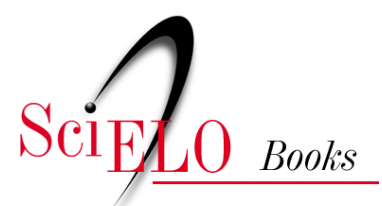

\title{
42. Gaspar Vianna, Mártir da Ciência e Benfeitor da Humanidade
}

\author{
Joffre Marcondes de Rezende
}

\section{SciELO Books / SciELO Livros / SciELO Libros}

REZENDE, J. M. Gaspar Vianna, Mártir da Ciência e Benfeitor da Humanidade. In: ’’ sombra do plátano: crônicas de história da medicina [online]. São Paulo: Editora Unifesp, 2009, pp. 359-362. História da Medicina series, vol. 2. ISBN 978-85-61673-63-5. https://doi.org/10.7476/9788561673635.0043.

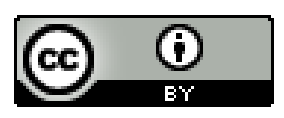

All the contents of this work, except where otherwise noted, is licensed under a Creative Commons Attribution 4.0 International license.

Todo o conteúdo deste trabalho, exceto quando houver ressalva, é publicado sob a licença Creative Commons Atribição 4.0.

Todo el contenido de esta obra, excepto donde se indique lo contrario, está bajo licencia de la licencia Creative Commons Reconocimento 4.0. 


\section{2 \\ Gaspar Vianna, Mártir da Ciência e Benfeitor da Humanidade*}

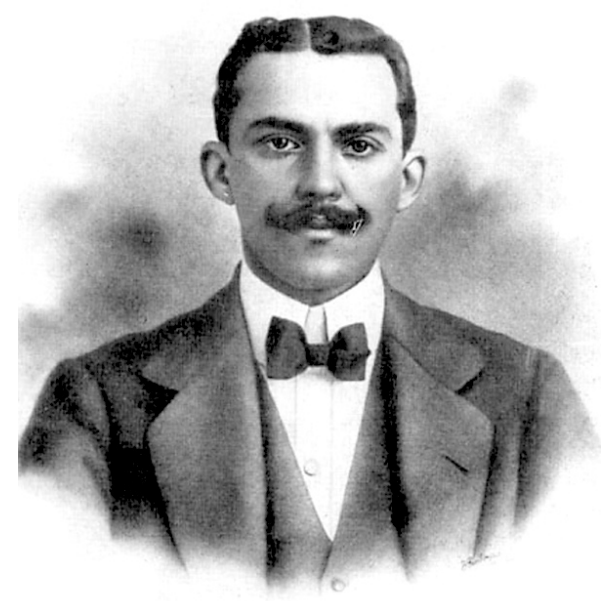

Gaspar Vianna (I885-I9I4).

$\mathrm{E}$ m sua breve vida de apenas 29 anos, Gaspar de Oliveira Vianna consagrou-se como um dos mais geniais cientistas na história da medicina brasileira. Natural de Belém, Pará, estudou medicina na Faculdade de Medicina do Rio de Janeiro. Desde o início do curso, sentiu-se atraído para as atividades de laboratório. No segundo ano, foi aluno de Chapot-Prevost, respeitado cirurgião na época e também professor de Histologia. Além das demonstrações práticas constantes do programa curricular, Chapot-Prevost estava sempre pronto a atender pessoalmente os alunos e seu laboratório permanecia aberto, inclusive aos domingos e feriados, à disposição dos alunos interessados. Cedo, Vianna se destacava em sua turma, principalmente na parte prática, em que dominava as técnicas de preparo do material e de coloração. Organizou por iniciativa própria uma rica coleção de preparações microscópicas, que, a pedido de Chapot-Prevost, foi doada ao laboratório de histologia da faculdade para fins didáticos.

* Publicado em Ética Revista, 5 (I), pp. 2I-22, 2008. 
Antes mesmo de terminar o curso de graduação, Gaspar Vianna deu aulas particulares de histologia para alunos do segundo ano. Foram seus alunos Magarinos Torres e Lauro Travassos, que se tornariam igualmente grandes cientistas do Instituto Oswaldo Cruz.

Em 1907, vagando o lugar de assistente da Seção de Patologia do Hospital Central de Alienados, Gaspar Vianna prestou concurso para preenchimento da vaga, tendo sido classificado em primeiro lugar e nomeado a seguir. Era chefe da seção o prof. Bruno Lobo, que também contribuiu para a sua formação. Sob a orientação deste grande mestre, realizou estudos sobre a célula nervosa, que serviriam para a sua tese de doutoramento, intitulada Estrutura da Célula de Schwann nos Vertebrados, defendida em I909.

Aos poucos, como autodidata, Gaspar Vianna tornou-se exímio histopatologista aproveitando os recursos de que dispunha no laboratório do Hospital de Alienados para estudar material que coletava na Santa Casa de Misericórdia.

Terminando o curso médico, foi convidado por Juliano Moreira, diretor do hospital para ali permanecer como patologista, porém, Oswaldo Cruz, que já tivera informações sobre o seu potencial, o chamou para integrar a plêiade de jovens cientistas que estava arregimentando para o Instituto de Manguinhos (Bacellar, 1963, pp. 202-209).

Naquele ano de 1909, Carlos Chagas havia descoberto a tripanosomíase americana e Gaspar Vianna foi incumbido, e entusiasmou-se com a ideia, de estudar a nova enfermidade em seus aspectos anatomopatológicos. Dedicou-se em tempo integral a esta tarefa e, em pouco tempo, estabeleceu as bases da patologia da doença de Chagas. Descreveu as lesões nos tecidos parasitados e descobriu a fase evolutiva do Trypanosoma cruzi nos vertebrados, de multiplicação intracelular "por divisões binárias sucessivas sob a forma de leishmanias e sua transformação em tripanosomas ainda no interior da célula", o que corresponde, na nomenclatura atual, a amastigotas e tripomastigotas (Vianna, I9II, pp. 276-293).

Simultaneamente com seus estudos sobre a tripanossomíase, Gaspar Vianna interessou-se pela leishmaniose, endemia que grassava no oeste paulista, na região de Bauru, conhecida como úlcera de Bauru, que dificultava a abertura da via férrea ligando aquela cidade ao estado de Mato Grosso. 
Em r909, A. Carini e U. Paranhos e, independentemente, A. Lindenberg, relataram o achado da Leishmania tropica em casos de úlcera de Bauru, identificando-a à leishmaniose de países do Oriente Médio, denominada botão do oriente.

Em I9I I, no mesmo ano em que publicava seu clássico trabalho sobre a anatomia patológica da tripanossomíase, descreveu uma nova espécie de leishmania, a que denominou Leishmania braziliensis, diferenciando-a da Leishmania tropica (Falcão, I962).

A leishmaniose cutâneo-mucosa, uma doença grave que acomete principalmente a face e as mucosas da boca e do nariz, deformante, de evolução progressiva, não dispunha, até então, de tratamento eficaz. Apesar de ser patologista, Gaspar Vianna, inconformado com a inexistência de uma terapêutica eficaz, decidiu realizar pesquisas nesse sentido.

Depois de experimentar sem êxito o Salvarsan, um composto de arsênico então utilizado no tratamento da sífilis, teve a ideia de usar um composto de antimônio, cuja ação parasiticida já era conhecida. Optou pelo tartarato duplo de antimônio e potássio, denominado nas farmacopeias de tártaro emético.

O tártaro emético deve seu nome à sua ação emetizante, provocando vômitos, e foi muito usado desde a Antiguidade até o século XIX, quando foi abandonado por seus efeitos tóxicos semelhantes aos dos sais de arsênico.

Receoso de acidentes, empregou de início soluções muito diluídas, começando por I: I ooo e aumentando progressivamente sua concentração, até I:IOO, que foi bem tolerada pelos doentes. O medicamento era administrado em injeções intravenosas de $10 \mathrm{ml}$, repetidas a intervalos até a completa cicatrização das lesões. Vianna apresentou sua descoberta ao viı Congresso Brasileiro de Medicina e Cirurgia, realizado em Belo Horizonte, em abril de I9I 2 (Vianna, I9I2, pp. 426-428).

Em I9I3 apresentou à Faculdade de Medicina do Rio de Janeiro um trabalho sobre a doença de Posada-Wernicke, com o qual obteve o título de livre-docente com aprovação unânime da congregação (Ribeiro, I940, pp. I40-I42).

Comprovada a eficácia desta terapêutica na leishmaniose cutâneo-mucosa, a mesma foi empregada com igual sucesso na leishmaniose visceral (calazar) e no granuloma venéreo. 
Em sua curta existência, realizou ainda Gaspar Vianna outros estudos sobre várias espécies de tripanosomas, sobre o ainhum, a moléstia de Posadas-Wernick e algumas micoses. Em colaboração com Arthur Moses, descreveu uma nova micose humana causada por um fungo ainda não descrito, o Proteumyces infestans.

Gaspar Vianna era um trabalhador infatigável, que se dedicava de corpo e alma às pesquisas que empreendia. Seu prematuro falecimento decorreu de seu próprio trabalho. Em abril de I9I4, ao realizar a autópsia de um caso de tuberculose pulmonar, incisou o tórax e a pleura e recebeu no rosto um jato do líquido que se encontrava sob pressão na cavidade torácica. Poucos dias depois manifestou os sintomas de tuberculose miliar aguda, vindo a falecer dois meses após o incidente, em I4 de junho de I9I4 (Bacellar, op. cit.).

Gaspar Vianna é considerado um mártir da ciência e um benfeitor da humanidade por sua descoberta da cura da leishmaniose, que causava milhares de vítimas em todo o mundo.

\section{Referências Bibliográficas}

BaCellar, R. C. Brazil's Contribution to Tropical Medicine and Malaria. Rio de Janeiro, Gráfica Olímpica Editora, I963.

Falcão, E. C. Opera Omnia de Gaspar Vianna. São Paulo, Revista dos Tribunais, I 962. Ribeiro, L. "Gaspar de Oliveira Vianna”. Medicina no Brasil. Rio de Janeiro, Imprensa Nacional, I940.

Vianna, G. "Contribuição para o Estudo da Anatomia Patolojica da Moléstia de Carlos Chagas”. Memórias do Instituto OswaIdo Cruz, 3, pp 276-293, I9I I.

. "Tratamento da Leishmaniose Tegumentar com Injecções Intravenosas de Tártaro Emético”. Anais do VII Congresso Brasileiro de Medicina e Cirurgia, 4 (3), pp. 426-428, I9I2. 